\section{A review of "approach of Turkish ophthalmologists to micronutrition in age-related macular degeneration"}

\author{
Um comentário para abordagem dos \\ oftalmologistas turcos em relação a \\ micronutrição na degeneração macular \\ relacionada à idade
}

\section{Dear Editor:}

We read with interest the article "Approach of Turkish ophthalmologists to micronutrition in age-related macular degeneration" by Şahın et al..$^{(1)}$ They aimed to evaluate the knowledge and behavior of ophthalmologists in Turkey with regard to micronutrition support in patients with age-related macular degeneration (ARMD). We congratulate the authors on their well-designed study. We would, however, like to make some contributions and report some inconsistencies in the article.

Different risk factors were defined for ARMD such as older age, ultraviolet light, genetic predisposition, smoking, and nutrient deficiency $^{(2)}$. Many studies have investigated the use of vitamins and antioxidants, such as lutein, omega-3, zeaxanthin, zinc, vitamin E, and vitamin $C$, in the treatment of ARMD; the best known studies include the Age-related Eye Disease Study (AREDS) and AREDS2 $2^{(3-5)}$. AREDS revealed a significant effect of zinc and antioxidants on the development of advanced age-related macular degeneration (AMD) in patients with early signs of the disease and recommended their use in at-risk patients (categories 3 and 4). AREDS2 further examined the effects of carotenoids and omega-3 long-chain fatty acids in patients at risk of $A R M D^{(4)}$.

The present study by Sahin et al. shows that the results of the aforementioned valuable studies have not been accurately understood and analyzed by most ophthalmologists, even by retina and uvea specialists ${ }^{(1)}$. The authors report that micronutrients are mostly prescribed by general ophthalmologists. However, $56,3 \%$ of the ophthalmologists stated that they did not use the AREDS criteria, and 10,1\% and $1,7 \%$ used micronutrients for grade $1-2$ and grade 5 patients with $A M D$, respectively. This means that several ophthalmologists prescribe these expensive drugs in spite of scientific facts, and many patients use these drugs although not beneficial to them.

We believe that another explanation as to why retina and uvea specialists prescribe micronutrients less than general ophthalmologists is that these specialists see more patients with neovascular ARMD than general ophthalmologists, and these patients make up an important part of their patient cohort. However, the use of micronutrients is not effective for these patients, so retina and uvea specialists may be less prone to prescribing these drugs than general ophthalmologists. Indeed, the mean number of patients seen per month and patients with ARMD seen per month are also important factors.

Additionally, the authors asked the participants about the frequency of prescribing micronutrients, and the reply options were "always," "frequently," "occasionally," and "never." We think that these options are quite subjective and that the meaning of always, frequently, occasionally, and never may be differently perceived by each participant. Instead of this, a scale ranging from 0 to 10 showing the number of micronutrient prescriptions for each of 10 AMD patients would be a more scientific approach (mean number of micronutrient prescription/10 AMD patients: 0/10, 1/10,..., 9/10, 10/10).

We would also wish to report that the number of participants indicated in the article is inconsistent, and we believe that this error was made by mistake. In the results section, the authors mentioned that the number of participants was 249, with 158 being males and 85 being females. However, the sum of 158 and 85 is 243. Additionally, the total number of participants is given as 243 and 240 in table 1, 247 in table 2, and 246 in table 3.

Yakup Aksoy ${ }^{1}$ Mehmet Koray Sevinc ${ }^{2}$

Submitted for publication: March 31, 2015

Accepted for publication: April 2, 2015

${ }^{1}$ Ophthalmology Department, Girne Military Hospital, Girne, Cyprus.

2 Ophthalmology Department, Gulhane Medical School, Ankara, Turkey.

Funding: No specific financial support was available for this study.

Disclosure of potential conflicts of interest: None of the authors have any potential conflict of interest to disclose.

Corresponding author: Yakup Aksoy. Ophthalmology Department- Girne Military Hospital, Girne, Cyprus E-mail: dryakupaksoy@gmail.com

\section{REFERENCES}

1. Şahin M, Yüksel H, Şahin A, Cingü AK, Türkcü FM, Özkurt ZG, et al. Approach of Turkish ophthalmologists to micronutrition in age-related macular degeneration. Arq Bras Oftalmol. 2015:78(1):10-4.

2. Nano ME, Lansingh VC, Pighin MS, Zarate N, Nano H, Carter MJ, et al. Risk factors of age-related macular degeneration in Argentina. Arq Bras Oftalmol. 2013;76(2):80-4.

3. Serracarbassa PD. Vitamins and antioxidants in age-related macular degeneration. Arq Bras Oftalmol. 2006;69(3):443-5

4. Age-Related Eye Disease Study 2 Research Group. Lutein + zeaxanthin and omega-3 fatty acids for age-related macular degeneration: the Age-Related Eye Disease Study 2 (AREDS2) randomized clinical trial. JAMA. 2013;309(19):2005-15.

5. Damico FM, Gasparin F, Scolari MR, Pedral LS, Takahashi BS. New approaches and potential treatments for dry age-related macular degeneration. Arq Bras Oftalmol. $2012 ; 75(1): 71-6$ 